\title{
Hypoxia-Induced Inflammatory Chemokines in Subjects with a History of High-Altitude Pulmonary Edema
}

\author{
K. P. Mishra $\cdot$ Navita Sharma $\cdot$ Poonam Soree $\cdot$ \\ R. K. Gupta $\cdot$ Lilly Ganju $\cdot$ S. B. Singh
}

Received: 14 January 2015/Accepted: 27 February 2015/Published online: 14 March 2015

(C) Association of Clinical Biochemists of India 2015

\begin{abstract}
High altitude hypoxia is known to induce an inflammatory response in immune cells. Hypoxia induced inflammatory chemokines may contribute to the development of high altitude pulmonary edema (HAPE) by causing damage to the lung endothelial cells and thereby capillary leakage. In the present study, we were interested to know whether chronic inflammation may contribute to HAPE susceptibility. We examined the serum levels of macrophage inflammatory protein-1 $\alpha$ (MIP-1 $\alpha$ ), monocyte chemoattractant protein-1 (MCP-1) and interleukin-8 in group (1) HAPE Susceptible subjects $(\mathrm{n}=20)$ who had past history of HAPE and group (2) Control $(n=18)$ consist of subjects who had stayed at high altitude for 2 years without any history of HAPE. The data obtained confirmed that circulating MCP-1, MIP- $1 \alpha$ were significantly upregulated in HAPE-S individuals as compared to the controls suggestive of chronic inflammation. However, it is not certain whether chronic inflammation is cause or consequence of previous episode of HAPE. The moderate systemic increase of these inflammatory markers may reflect considerable local inflammation. The existence of enhanced level of inflammatory chemokines found in this study support the hypothesis that subjects with past history of HAPE have higher baseline chronic inflammation which may contribute to HAPE susceptibility.
\end{abstract}

Keywords HAPE $\cdot$ Inflammation $\cdot \mathrm{AMS} \cdot \mathrm{SpO}_{2}$. Chemokines

K. P. Mishra $(\bowtie) \cdot$ N. Sharma $\cdot$ P. Soree

R. K. Gupta · L. Ganju · S. B. Singh

Immunomodulation Laboratory, Defence Institute of Physiology

\& Allied Sciences, Lucknow Road, Timarpur, Delhi 110054,

India

e-mail: kpmpgi@rediffmail.com

\section{Introduction}

High altitude pulmonary edema (HAPE), a severe form of acute mountain sickness occurs after rapid ascent to altitudes in excess of $2700 \mathrm{~m}$ above sea level [1-4]. This form of noncardiogenic pulmonary edema is rare and is sometimes complicated with cerebral edema. HAPE generally affects healthy young people, some of whom suffer recurrent episodes $[5,6]$. It often occurs at moderate altitudes. For these reasons, it has been speculated that a constitutional susceptibility underlies the development of this disease. Any local or systemic inflammation is not present at the onset of HAPE however it occurs in later stages [7-9]. Studies on high pulmonary artery pressure suggest that inflammation or decreased fluid clearance from the lung may contribute to the development of HAPE [10-12]. It is known that hypoxia stimulates the expression of inflammatory cytokines and chemokines in macrophages and endothelial cells in vitro and enhances NK-cell activity in humans exposed to high altitude [13-17].

Chemokines are a superfamily of small proteins that are important in recruiting and activating leukocytes during inflammation [18]. The chemokines MIP- $1 \alpha$ and MCP-1 attract mainly mononuclear phagocytes $[19,20]$. They are the important immune response modulators that may be affected by high altitude exposure. They play a central role in the immune response by promoting the activation of antigen specific and non-specific effector mechanism and tissue repair. Selective cytokine and chemokine production can determine the outcome of a response by stimulating protective or exacerbative immune mechanism. On the other hand, they can be harmful when produced in excess by causing overproduction of inflammatory cells, fever, vascular leakage, tissue damage and lethal shock. Multiple levels of cytokine and chemokines gene regulation 
therefore exist to ensure that, in most circumstances, inflammatory markers synthesis is limited in time and space.

Therefore, the goal of the present study was to examine if exposure to hypoxia causes an inflammatory response in individuals who were HAPE-S and who did not suffer HAPE after going to high altitude. Using sensitive assays we were indeed able to show elevated levels of circulating chemokines, which could be involved in a possible subsequent development of HAPE in susceptible individuals.

\section{Materials and Methods}

Study Subjects

HAPE-S: HAPE Susceptible subjects had past history of high altitude pulmonary edema with radiological documentation in last 5 years. The mean age of HAPE-S individuals $(\mathrm{n}=20)$ was 32.4 (SE 1.46, age range 25-48 years). Control:Control group consist of subjects who had stayed at high altitude for 2 years without any history of HAPE. The mean age of control individuals $(\mathrm{n}=18) \quad$ was 27.72 years $\quad$ (SE: 1.44 , age range 23-45 years). Both groups of soldiers of army were air inducted to altitude of $3400 \mathrm{~m}$ (Northern Himalayas, in extreme cold environment) and had followed acclimatization schedule which allowed gradual increase in physical activity. Even after following acclimatization schedule, HAPE-S subjects suffered from HAPE. Therefore, a retrospective study was designed to identify biomarkers to predict susceptibility to HAPE. HAPE-S, and control subjects were subjected to normobaric hypoxia $\left(\mathrm{FiO}_{2}=0.12\right)$ and evaluated for inflammatory chemokines. The study was approved by institute Ethical Committee. Informed consent was obtained from each individual (Table 1).

\section{Measurement of Peripheral Blood Oxygen Saturation}

The subjects were investigated in the supine position while breathing synthetic gas mixture consisting of $12 \%$ oxygen $\left(\mathrm{FiO}_{2}=0.12\right)$ mixed in nitrogen. The hypoxic gas mixture correspond to the altitude of $4500 \mathrm{~m}$. Inhalation was performed via a tight fit face mask. Peripheral oxygen saturation $\left(\mathrm{SpO}_{2}\right)$ was recorded before and at the end of

Table 1 Demography of subjects

\begin{tabular}{llll}
\hline Group & Number & Mean age \pm SE & Age range (years) \\
\hline Control & 18 & $27.72 \pm 1.43$ & $23-45$ \\
HAPE-S & 20 & $32.40 \pm 1.46$ & $25-48$ \\
\hline
\end{tabular}

30 min exposure of hypoxic stress by using multiparameter monitor, BPL India.

\section{Blood Collection and Serum Separation}

Venous blood was drawn and collected in unheparinised vials and kept for $1 \mathrm{~h}$ at $4{ }^{\circ} \mathrm{C}$. The blood clotted, leaving a clear serum above. This serum was collected in fresh eppendorf tubes and centrifuged at $1200 \mathrm{rpm}$ for $10 \mathrm{~min}$. Red blood cells if any were pelleted down by centrifugation. The serum was collected in small aliquots and stored at $-40{ }^{\circ} \mathrm{C}$ for further analysis.

Estimation of Chemokines

Macrophage inflammatory protein- $1 \alpha$ (MIP- $1 \alpha$ ), MCP-1 and IL-8 expression levels were quantified by means of a cyto-fluorimetry-based ELISA system (flowcytomix, ebiosciences, USA). In brief, human serum was kept at $-80{ }^{\circ} \mathrm{C}$ until used. Chemokines were estimated according to the manufacturer's instructions. The samples were acquired in BD FACS-Caliber and analyzed using flowcytomix pro software.

\section{Statistical Analysis}

Values are represented as mean \pm SE. Comparison between results from HAPE-S and controls were performed using Mann-Whitney test. All analysis were conducted using SPSS 16 software. The $p$ value of $\leq 0.05$ was considered significant.

\section{Result}

Analysis of Peripheral Oxygen Saturation $\left(\mathrm{SpO}_{2}\right)$

The Mean $\mathrm{SpO}_{2}$ level of HAPE-S subjects were $98.25 \pm 0.315 \%$ in baseline and $69.65 \pm 2.1 \%$ in hypoxic exposure $\left(\mathrm{FiO}_{2}=0.12\right)$ while control subjects have $98.56 \pm 0.166 \%$ in baseline level and $76.30 \pm 1.3 \%$ in hypoxic exposure. The HAPE-S subjects showed a significant fall in $\mathrm{SpO}_{2}(p<0.05)$ as compared to control in Hypoxia (Fig. 1).

\section{Analysis of Chemokines}

The pro-inflammatory chemokines MIP-1 $\alpha$, MCP-1 were significantly increased in the HAPE-S individuals as compared to the controls. The IL- 8 level was upregulated in HAPE-s individuals but it was not significant. The base line level of MIP-1 a concentration in HAPE-S individuals $(286 \pm 79 \mathrm{pg} / \mathrm{ml}, \mathrm{n}=20, p=0.01)$ was higher as compared 


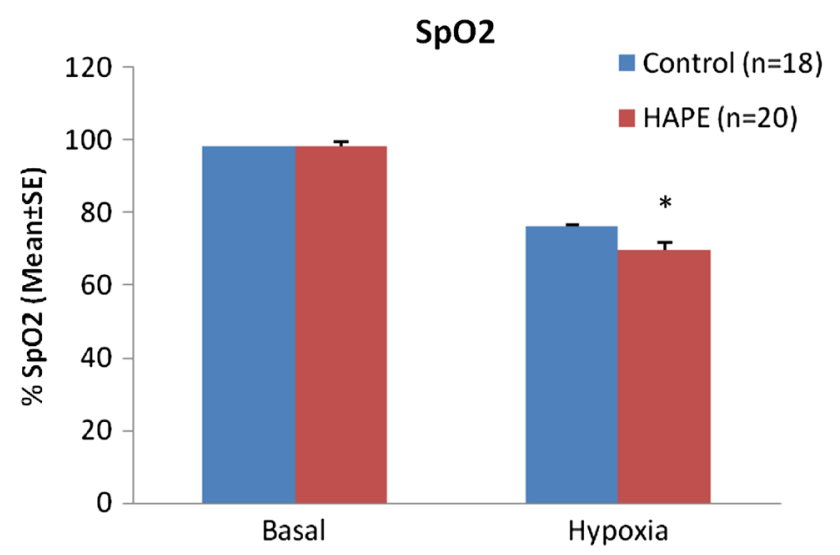

Fig. 1 Measurement of $\mathrm{SpO}_{2}$ in HAPE-S and control subjects $\left({ }^{*} p<0.05\right)$

to the control subjects $(176 \pm 138 \mathrm{pg} / \mathrm{ml}, \mathrm{n}=18)$. When the HAPE-S were subjected to Hypoxia $\left(\mathrm{FiO}_{2}=0.12\right)$ the level significantly increased to $(931 \pm 502 \mathrm{pg} / \mathrm{ml}, \mathrm{n}=20$, $p=0.05)$ as compared to control (197 $\pm 139 \mathrm{pg} / \mathrm{ml}, \mathrm{n}=18)$ (Fig. 2).

The base line level of MCP-1 concentration in HAPE-S individuals $(1836 \pm 738 \mathrm{pg} / \mathrm{ml}, \mathrm{n}=20, p=0.01)$ was significantly higher as compared to the control subjects $(1632 \pm 967 \mathrm{pg} / \mathrm{ml}, \mathrm{n}=18)$. When the HAPE-S were subjected to Hypoxia $\left(\mathrm{FiO}_{2}=0.12\right)$ the level significantly increased to $(3977 \pm 2471 \mathrm{pg} / \mathrm{ml}, \mathrm{n}=20, p=0.05)$ as compared to control (1833 $\pm 1017 \mathrm{pg} / \mathrm{ml}, \mathrm{n}=18)($ Fig. 3).

The base line level of IL-8 concentration in HAPE-S individuals $(726 \pm 395 \mathrm{pg} / \mathrm{ml}, \mathrm{n}=20, p=0.01)$ was higher as compared to the control subjects $(30 \pm 15 \mathrm{pg} / \mathrm{ml}$, $\mathrm{n}=18$ ) though it was not significant. When the HAPE-S were subjected to Hypoxia $\left(\mathrm{FiO}_{2}=0.12\right)$ the level became $(702 \pm 378 \mathrm{pg} / \mathrm{ml}, \mathrm{n}=17)$ as compared to control $(163 \pm 61 \mathrm{pg} / \mathrm{ml}, \mathrm{n}=16)$ (Fig. 4).

\section{Discussion}

High altitude environment may affect immune homeostatic mechanisms and immunoregulatory activities that may lead to High altitude associated diseases. This is a fact that hypoxia can induce inflammation and has general acceptance from studies of the hypoxia signalling pathway [16].

In the present study, we found that HAPE-S individuals who had a previous history of HAPE showed a marked decrease in peripheral capillary oxygen saturation $\mathrm{SpO}_{2}$ $(69.65 \pm 2.1 \%)$ in comparison to the control individuals $(76.30 \pm 1.3 \%)$ after exposure to $12 \%$ oxygen $\left(\mathrm{FiO}_{2}=0.12\right)$ corresponding to the height of $4500 \mathrm{~m}$. Reason may be attributed to the fact that there is an anatomical shunt and/or diffusion impairment and ventilationperfusion mismatch [21].

There is also an extra vascular lung water accumulation and/or inflammatory changes in the peripheral airways leading to decreased $\mathrm{SpO}_{2}$ [11]. Maggiorini et al. [22] has reported that increased capillary pressures (possibly with focal areas of stress failure) lead to secondary inflammatory changes. Significantly enhanced levels of inflammatory chemokines MIP-1 $\alpha$ and MCP-1 in HAPE-S individual as compared to the controls was observed after exposure to $12 \%$ hypoxia. Our study confirmed the moderate systemic inflammation in HAPE-S individuals. MIP$1 \alpha$ and MCP-1 chemokines are known to be reliable and
Fig. 2 Estimation of MIP-1 $1 \alpha$ chemokine in the serum of HAPE-S and control subjects. Basal level of serum MIP-1 $\alpha$ showed significantly $\left({ }^{*} p<0.01\right)$ higher level as compared to control; when control and HAPE-S individuals were subjected to $0.12 \mathrm{FiO}_{2}$, HAPE-S individuals showed significantly $\left({ }^{\#} p<0.05\right)$ higher level of MIP-1 $\alpha$

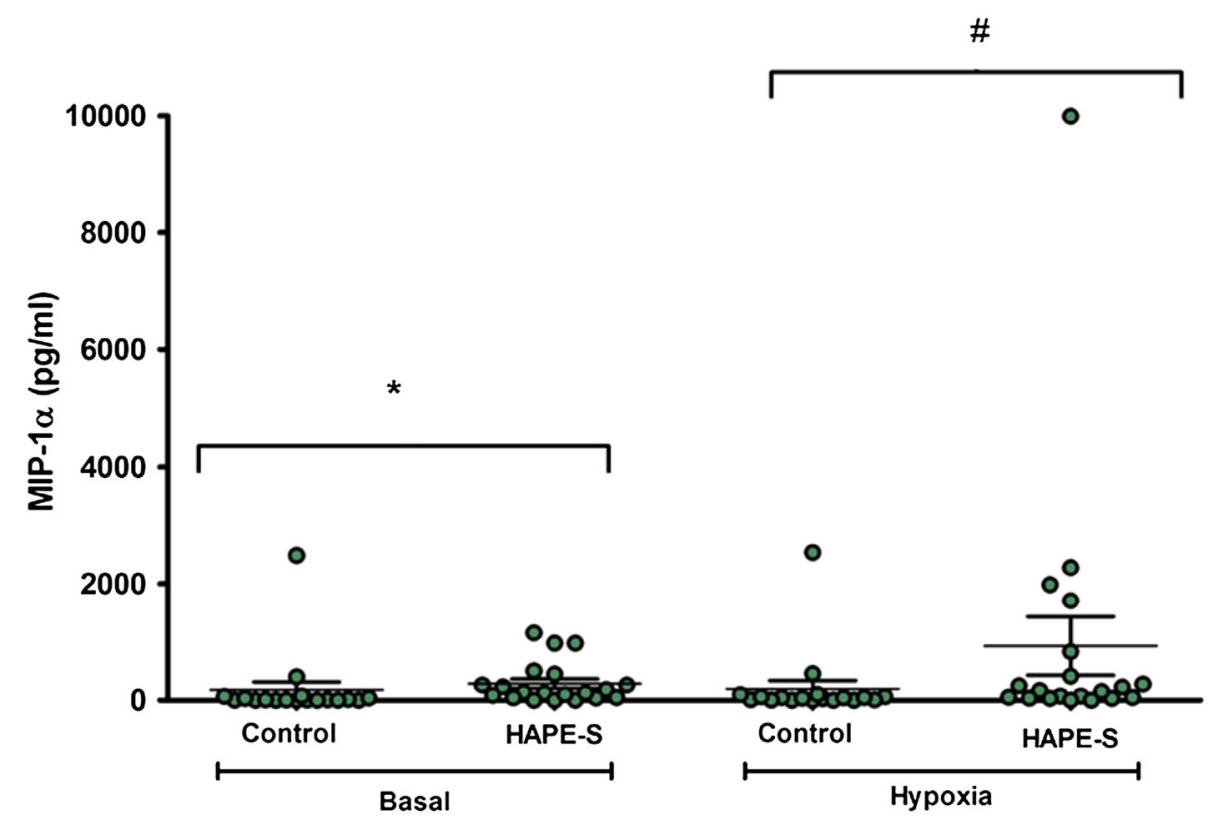


Fig. 3 Estimation of MCP-1 chemokine in the serum of HAPE-S and control subjects. Basal level of serum MCP-1 showed significantly $(* p<0.01)$ higher level as compared to control; when control and HAPE-S individuals were subjected to $0.12 \mathrm{FiO}_{2}$, HAPE-S individuals showed significantly $\left({ }^{\#} p<0.05\right)$ higher level of MCP-1

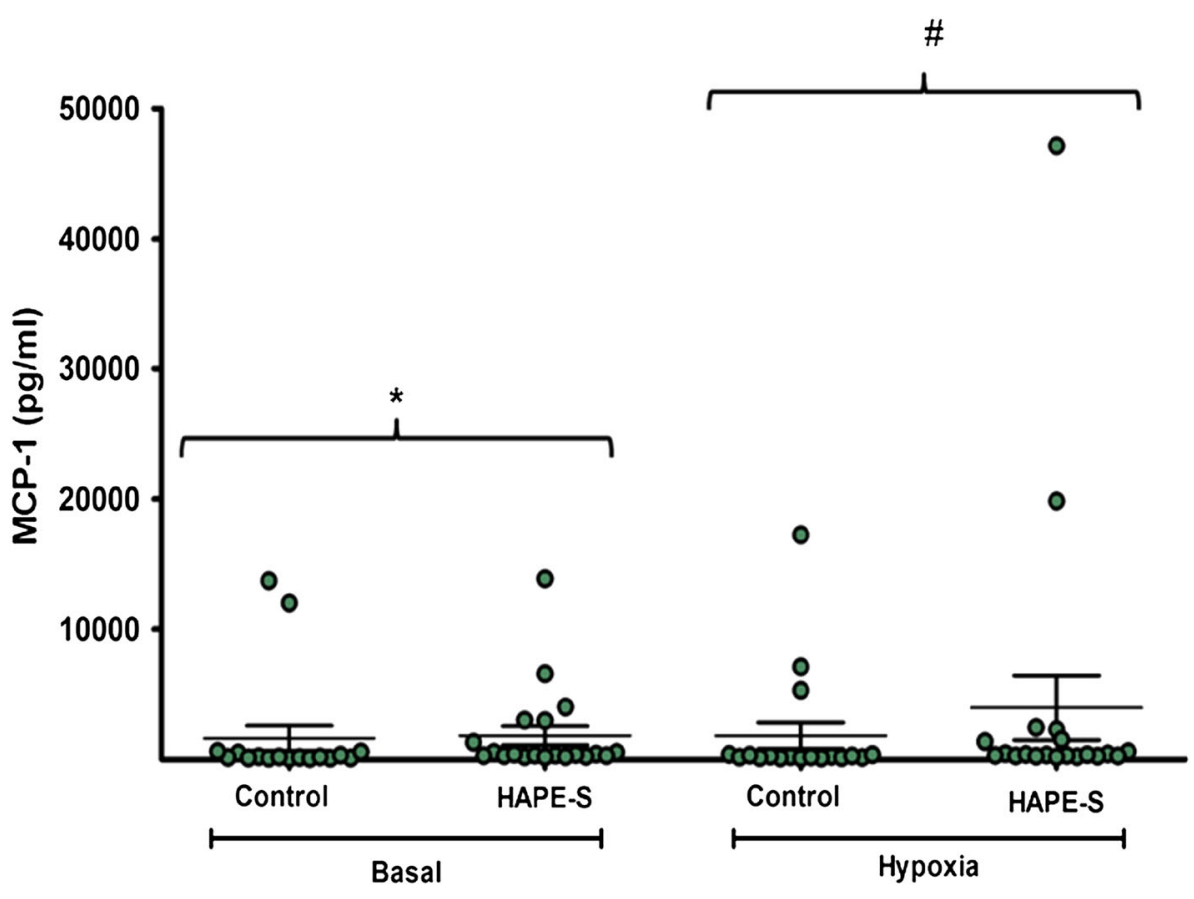

Fig. 4 Estimation of IL-8 chemokine in the serum of HAPE-S and control subjects. Basal level of serum IL-8 showed higher level but not significant as compared to control; when control and HAPE-S individuals were subjected to $0.12 \mathrm{FiO}_{2}$, HAPE-S individuals did not show significant enhancement in IL-8

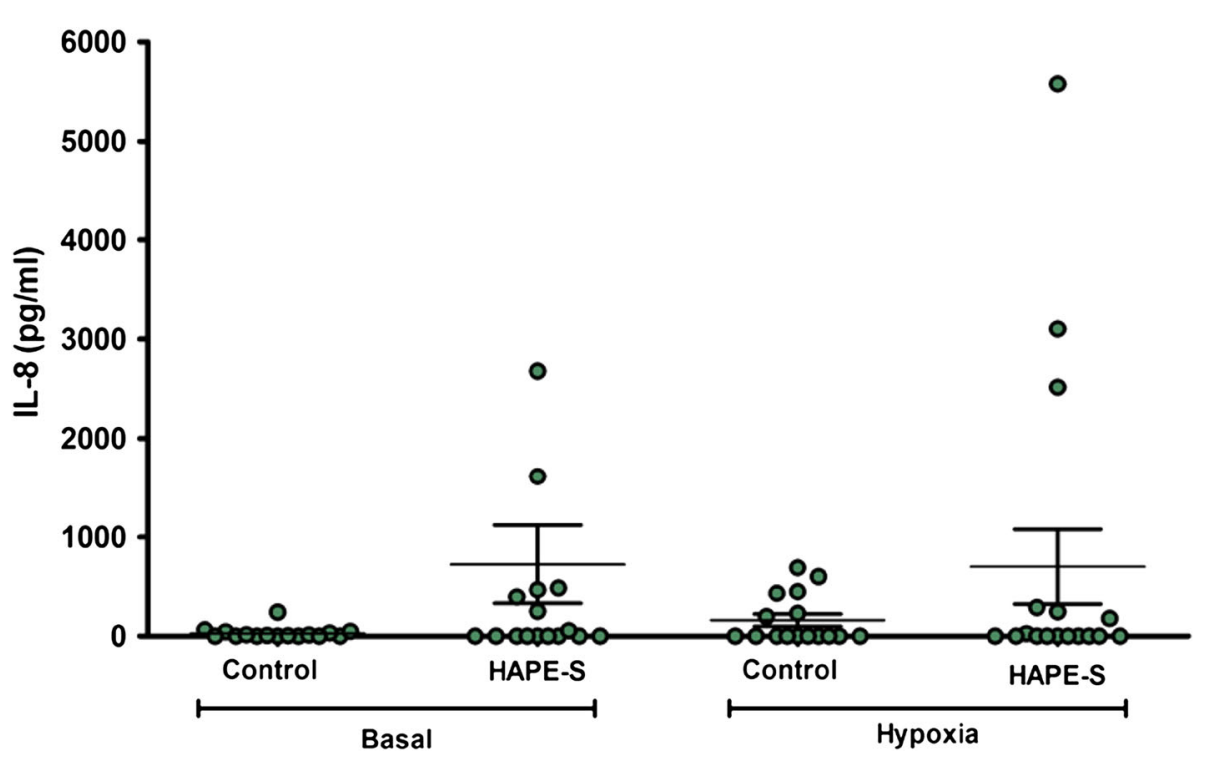

sensitive markers of systemic inflammation [23-25]. The level of interleukin-8 was also upregulated but it was not significant as compared to the control. Chemokines may act at multiple levels including leukocyte trans endothelial migration, leukocyte positioning within microenvironments and both phagocyte and lymphocyte activation. They may function beneficially, for example in tissue repair or harmfully in the setting of chronic inflammation. MCP-1 is critical mediators in the evolution of chronic inflammation. Circulating inflammatory chemokines induces the production of the acute phase response leading to the inflammation in tissues [26].
Oxygen is critical for the human systems and hypoxia stimulates inflammatory mediators [27]. The available literature suggests that hypoxia synergizes with different immune stimuli for the production of inflammatory mediators in human peripheral blood mononuclear cells and alveolar macrophages [28-30]. In persons with mountain sickness, for example, levels of circulating proinflammatory indicators increase, and vascular leakage of fluid causes pulmonary or cerebral edema [31, 32]. Hartmann et al. [16] reported the increased serum levels of inflammatory mediators for example interleukin-6, and C-reactive protein in healthy volunteers who spent 3 nights at an elevation higher 
than $3400 \mathrm{~m}$. Animal studies also indicate vascular leakage, accumulations of inflammatory cells in multiple organs, and elevated serum levels of inflammatory mediators in mice after short-term exposure to low oxygen concentrations [33]. The other immune cell activity such as NK-cell is enhanced in humans exposed to high altitude [34]. Hartmann et al. [16] reported that the existence and the kinetics of high altitude-induced cytokines support the hypothesis that inflammation is involved in the development of HAPE. In agreement with them, our study also confers that increased level of inflammatory markers may be involved in the susceptibility of the individuals to HAPE development.

Thus, hypoxia functions as a danger signal for the immune system by inducing the synthesis of inflammatory mediators in different cell types and tissues [35]. The responses to low oxygen concentration have been evolved as a physiological mechanism to detect tissue injury and to improve tissue repair. However, these responses are potentially harmful if environmental oxygen decreases at high altitude. MIP-1 $\alpha$, MCP-1 and IL- 8 are known to precede acute phase response to an inflammatory stimulus [36]. Roach et al. [37] demonstrated elevated levels of anti inflammatory markers in individuals less susceptible to high altitude induced diseases. The Protective effects of anti inflammatory markers indicate that inflammation is important in pathophysiology of high altitude illness. There has been recent interest in the concept that inflammation may contribute to the development of severe forms of high altitude illnesses. In addition, hypobaric hypoxemia has been shown to result in elevated levels of inflammatory and anti inflammatory marker in those susceptible and resistant to altitude illness, respectively [16, 38, 39].

This study is, to our knowledge, the first to focus on the chemokines level in HAPE-S individuals. The data obtained suggest that circulating MCP-1, MIP- $1 \alpha$ were significantly upregulated in HAPE-S individuals as compared to the controls. The moderate systemic increase of these inflammatory markers may reflect considerable local inflammation. The existence of enhanced level of inflammatory chemokines MCP-1 and MIP-1 $\alpha$ could be an important biomarker for HAPE-susceptibility. This study confers that HAPE recovered subjects are more prone to HAPE after re-entry to high altitude.

Acknowledgments Authors are thankful to the Defence Research and Development Organization (DRDO), Ministry of Defence, Govt. of India for the grants in form of Project DIP-251.

Conflict of interest The authors report no conflict of interest.

\section{References}

1. Houston CS. Acute pulmonary edema of high altitude. N Engl J Med. 1960;263:478-80.
2. Hackett PH, Rennie D, Levine HD. The incidence, importance, and prophylaxis of acute mountain sickness. Lancet. 1976;2: 1149-55.

3. Grover RF, Hyers TM, McMurtry IF, Reeves JT. High-altitude pulmonary edema. In: Fishman AR, Renkin EM, editors. Pulmonary edema. Bethesda: American Physiological Society; 1979. p. 229-39.

4. Hanaoka M, Tanaka M, Ge RL, Droma Y, Ito A, Miyahara T, et al. Hypoxia-induced pulmonary blood redistribution in subjects with a history of high-altitude pulmonary edema. Circulation. 2000; 101:1418-22.

5. Kafer ER, Leigh J. Recurrent respiratory failure associated with the absence of ventilator responses to hypercapnia and hypoxia. Am Rev Respir Dis. 1972;106:100-8.

6. Lakshminarayan S, Pierson DJ. Recurrent high altitude pulmonary edema with blunted chemosensitivity. Am Rev Respir Dis. 1975;111:869-72.

7. Swenson ER, Maggiorini M, Mongonin S, Gibbs JSR, Ilona G, Mairbaurl $\mathrm{H}$, et al. Pathogenesis of high altitude pulmonary edema inflammation is not an etiologic factor. JAMA. 2002;17: 2228-35.

8. Schoene RB, Hackett PM, Henderson W. High altitude pulmonary edema: characteristic of lung lavage fluid. JAMA. 1986;256:63-9.

9. Kubo K, Hanaoka M, Yamaguchi S, Hayano T, Hayasaka M, Koizumi $\mathrm{T}$, et al. Cytokines in bronchoalveolar lavage fluid in patients with high altitude pulmonary oedema at moderate altitude in Japan. Thorax. 1996;51:739-42.

10. Uchakin PN, Gotovtseve EP, Levine B, Stray-Gundersen J. Neuroimmunohumoral changes associated with altitude training (abstr). Med Sci Sports Exerc. 1995;27(Suppl):174.

11. Bartsch P. High altitude pulmonary edema. Respiration. 1997; 64:435-43.

12. Facco M, Zilli C, Siviero M, Ermolao A, Travain G, Baesso I, et al. Modulation of immune response by the acute and chronic exposure to high altitude. Med Sci Sports Exerc. 2005;37:768-74.

13. Ghezzi P, Dinarello CA, Bianchi M, Rosandich ME, Repine JE, White CW. Hypoxia increases production of interleukin-1 and tumor necrosis factor by human mononuclear cells. Cytokine. 1991;3:189-94.

14. Shreeniwas R, Koga S, Karakurum M, Pinsky D, Kaiser E, Brett $\mathrm{J}$, et al. Hypoxia-mediated induction of endothelial cell interleukin-1 alpha. An autocrine mechanism promoting expression of leukocyte adhesion molecules on the vessel surface. J Clin Investig. 1992;90:2333-9.

15. Karakurum M, Shreeniwas R, Chen J, Pinsky D, Yan SD, Anderson $\mathrm{M}$, et al. Hypoxic induction of interleukin- 8 gene expression in human endothelial cells. J Clin Investig. 1994;93:1564-70.

16. Hartmann G, Tschöp M, Fischer R, Bidlingmaier C, Riepl R, Tschöp K, Hautmann H, Endres S, Toepfer M. High altitude increases circulating interleukin-6, interleukin-1 receptor antagonist and C-reactive protein. Cytokine. 2000;12(3):246-52.

17. Mishra KP, Ganju L. Influence of high altitude exposure on the immune system: a review. Immunol Investig. 2010;39:219-34.

18. Schall TJ, Bacon KB. Chemokines, leukocyte trafficking, and inflammation. Curr Opin Immunol. 1994;6(6):865-73.

19. Schall TJ, Simpson NJ, Mak JY. Molecular cloning and expression of the murine RANTES cytokine: structural and functional conservation between mouse and man. Eur J Immunol. 1992; 22(6): 1477-81.

20. Rollins BJ, Yoshimura T, Leonard EJ, Pober J. Cytokine-activated human endothelial cells synthesize and secrete monocyte chemoattractant protein, MCP-1. Am J Pathol. 1990;136:1229-33.

21. Loeppky JA, Icenogle MV, Charlton GA, Conn CA, Maes D, Riboni K, et al. Hypoxemia and acute mountain sickness: which comes first? High Alt Med Biol Winter. 2008;9(4):271-9. 
22. Maggiorini M, Mélot C, Pierre S, Pfeiffer F, Greve I, Sartori C, et al. High-altitude pulmonary edema is initially caused by an increase in capillary pressure. Circulation. 2001;103(16):2078-83.

23. Adamik B, Zimecki M, Wlaszczyk A, Kubler A. Immunological status of septic and trauma patients: High tumor necrosis factor alpha serum levels in septic and trauma patients are not responsible for increased mortality; a prognostic value of serum interleukin 6. Arch Immunol Ther Exp. 1997;45:169-75.

24. Herrmann JL, Blanchard H, Brunengo P, Lagrange PH. TNF alpha, IL-1 beta and IL-6 plasma levels in neutropenic patients after onset of fever and correlation with the C-reactive protein (CRP) kinetic values. Infection. 1994;22:309-15.

25. Holger KE, Carmeliet P. Hypoxia and Inflammation. N Engl J Med. 2011;364(7):656-65.

26. Lloyd CM, Minto AW, Dorf ME, Proudfoot A, Wells TN, Salant DJ, et al. RANTES and monocyte chemoattractant protein-1 (MCP-1) play an important role in the inflammatory phase of crescentic nephritis, but only MCP-1 is involved in crescent formation and interstitial fibrosis. J Exp Med. 1997;185(7): 1371-80.

27. Yamauchi TK, Ihara Y, Ogata A, Yoshizaki K, Azuma J, Kishimoto T. Hypoxic stress induces cardiac myocyte-derived interleukin-6. Circulation. 1995;91:1520-4.

28. Hempel SL, Monick MM, Hunninghake GW. Effect of hypoxia on release of IL-1 and TNF by human alveolar macrophages. Am J Respir Cell Mol Biol. 1996;14:170-6.

29. Scannell G. Leukocyte responses to hypoxic/ischemic conditions. New Horiz. 1996;4:179-83.

30. VanOtteren GM, Standiford TJ, Kunkel SL, Danforth JM, Strieter RM. Alterations of ambient oxygen tension modulate the expression of tumor necrosis factor and macrophage inflammatory protein-1 alpha from murine alveolar macrophages. Am J Respir Cell Mol Biol. 1995;13:399-409.

31. Hackett PH, Roach RC. High-altitude illness. N Engl J Med. 2001;345:107-14.

32. Semenza GL. Life with oxygen. Science. 2007;318:62-4.

33. Thompson LF, Eltzschig HK, Ibla JC. Crucial role for ecto-5'nucleotidase (CD73) in vascular leakage during hypoxia. J Exp Med. 2004;200:1395-405.

34. Klokker M, Kharazmi A, Galbo H, Bygbjerg I, Pedersen BK. Influence of in vivo hypobaric hypoxia on function of lymphocytes, neutrocytes, natural killer cells, and cytokines. J Appl Physiol. 1993;74:1100-6.

35. Fandrey J. Hypoxia-inducible gene expression. Respir Physiol. 1995;101:1-10.

36. Arend WP, Malyak M, Guthridge CJ, Gabay C. Interleukin-1 receptor antagonist: role in biology. Annu Rev Immunol. 1998;16:27-55.

37. Roach RC, Bartsch P, Hackett PH, Oelz O. The Lake Louise acute mountain sickness scoring system. In: Sutton JR, Houston CS, Coates G, editors. Hypoxia and molecular medicine. Burlington: Queen City Press; 1993. p. 272-4.

38. Julian CG, Subudhi AW, Wilson MJ, Dimmen AC, Pecha T, Roach RC. Acute mountain sickness, inflammation, and permeability: new insights from a blood biomarker study. J Appl Physiol. 1985;111(2):392-9.

39. Mishra KP, Jain S, Ganju L, Singh SB. Hypoxic stress induced TREM-1 and inflammatory chemokines in human peripheral blood mononuclear cells. Indian J Clin Biochem. 2014;29(2): $133-8$. 